\title{
A practical case study exploring how flipped learning affects the development of problem-solving skills in two different disciplines
}

Malgorzata Iwaniec, Tatiana Simmonds, Zoe Swan

University of Greenwich, University of Brighton

\begin{abstract}
Flipped learning involves 'direct instruction moving from the group learning space to the individual learning space and the resulting group space being transformed into a dynamic, interactive learning environment, where the educator guides students as they apply concepts and engage creatively in the subject matter' Flipped Learning Network (2014).

This study explores how the flipped-learning pedagogy was introduced to two separate student groups within different disciplines - law and computing - and compares the findings that have begun to emerge in relation to the development of a range of skills, in particular the development of problem-solving skills. Analytical and problem-solving skills are key skills, not only for both law students and computing students, but also for any graduate.
\end{abstract}

The findings suggest that the flipped-classroom approach to teaching and learning can increase student participation and engagement; that it supports the development of critical thinking and problem-solving skills; that it promotes deeper levels of learning; that it encourages the development of independent study skills and provides opportunities for students to develop and practise the core skills required of the students by their discipline.

This paper also explores what both students and academics perceived as the challenges and what they regarded as the benefits of working with the flipped teaching and learning strategy during the academic year 2014/15.

\section{Keywords: Flipped Classroom, Higher Education, Problem-solving Skills, Law, Computing}

\section{Introduction}

With the recent consultations on the Teaching Excellence Framework (TEF) paper and removed student cap, universities are under more pressure than ever to be more responsive to the needs of employers. In the employer's eyes, graduates should be work- or industry-ready before they leave university (Pallis \& Ng, 2011; Bernett et al, 2001). Flipped learning is a contemporary yet fairly well-established pedagogical approach that, in an active learning environment and by extending the flipped-classroom approach, enhances students' learning and significantly develops the skills that students need for potential employment (Fulton, 2012; Strayer, 2012; Mazur, 2009). 
In recent years, the idea of the flipped classroom (FC) has sparked considerable discourse; as a method, it gained prominence following the early work of Harvard's Professor Mazur, who considered utilising text files and problem solving to allow learners to be in charge both of the content and the pace of the learning (Mazur, 1991). Subsequently, Bergmann and Sams adopted this approach as a way to "use class time for more student-centred and inquiry-based activities' facilitated by educators (Bergmann and Sams, 2012). Since then, sector-scanning reports have identified flipped classroom practices as important pedagogical developments (Sharples et al, 2014; NMC 2014). More specifically, the literature review also shows recent publication evidence of case studies, in the context of UK higher education, which advocate the use of the flipped classroom to help students to develop problem-solving skills (O'Flaherty \& Phillips, 2015; Little, 2015; Kong, 2014; James et al, 2014).

\section{Background research and theoretical framework}

In recent years, along with the expansion of technology-enhanced learning, the flipped classroom has become one of the most popular teaching approaches for fostering students' active and centred learning (Hamdam et al, 2013).

In essence, the flipped classroom provides (often via online/video/audio resources) prior instructional content (traditionally delivered by lecturers in class), so that students may use the freed-up class time for active engagement with knowledge construction and application: interacting with each other and the lecturer, they take part in such wide-ranging tasks and activities as problem solving, analysis, discussions and debates (Hamdam et al, 2013; Halili and Zainuddin 2015). This model of teaching, based on a revised Bloom's Taxonomy pyramid, shifts lower-level thinking skills (understanding and remembering) outside the classroom (where students can spend as much time as they need on comprehending the content) and brings the higher-order thinking skills (from analysing and applying to evaluating and creating) into class (Krathwohl, 2002; Kim et al, 2014; Davis et al, 2013).

An approach encouraging active engagement in lower- and higher-order tasks builds up skills and capabilities vital to students as graduates and allows them to take charge of their own learning (Halili and Zainuddin, 2015): from mere recipients of knowledge, they become active learners and critical, reflective and creative thinkers. Successful application of these skills results in the development of further intellectual capabilities that foster explanations, decisions and performances, which are valid within the context of available knowledge (Pogrow, 1990; Halili and Zainuddin, 2015).

By extension these intellectual capabilities describe problem-solving skills and, if students are to develop them, they need to be encouraged and taught in a way that at first involves lower-level skills as a foundation and then higher-order skills from application to evaluation (creating, judging, analysing, synthesising) for deeper understanding. As noted by Nederverd and Berge (2015), application of the higher-order cognitive domain of learning enhances and develops cognitive and problem-solving skills.

The method of delivering content prior to the class may vary: self-recorded short clips, lectures and/or selections from a vast library of OER resources in different formats (text, audio, and 
video). Content variation is vital, both to stimulate students' interest and to address their different learning styles, as is embedding activities and breaks to sustain their attention. The pre-class material having been assimilated, students can use their acquired knowledge to devote the liberated class time to applying concepts and practising relevant skills in activities facilitated by the lecturers (Kim et al, 2014; Davis et al, 2013).

Drawing on the notion of 'a guide on a side' (King, 1993), the lecturer's role changes to that of a designer and facilitator of learning, whilst the learning simultaneously becomes more studentcentred: with a facilitator at their side, to motivate, guide and provide continuous feedback on their activities and performance, students are more active and much more in control of their own learning (Bergmann and Sams, 2012).

A recent study by Asef-Vaziri (2015: 72), promoting the flipped classroom approach using a screen capture tool and active learning tasks in the classroom, concludes:

"By delivering lectures online, ... students can learn the material at a time and location of their choice, ... Live face-to-face in-class discussions ... offer a more active learning environment that is a result of better-prepared students. Class time is no longer spent teaching basic concepts, but rather on more value - added activities, such as problem solving, answering questions, systems thinking, and potentially on collaborative exercises such as case studies, Web based simulation games, and real - world application" (2015: 72).

Additionally, according to Mayer (2002), a meaningful learning environment where problemsolving skills can be applied may be created when students have knowledge and skills related to cognitive processes. He further suggests that the flipped classroom and active learning are at the very core of such learning environments.

The purpose of this paper is to share the results of two cohorts of students whose teachers adopted the flipped classroom model; it explores activities and techniques chosen and designed to make the most of the students' learning environments in developing their problem-solving skills. The following section introduces the learner experience in flipped classrooms facilitated by two lecturers from different disciplines.

\section{Learner experience}

The purpose of this case study is to explore how flipped learning supports students in developing problem-solving skills. This case study was conducted over a twelve-week period during the autumn term. As briefly summarised above, the research offers evidence that flipped learning can increase student participation and engagement, help develop critical thinking and problem-solving skills and promote deeper levels of learning.

The study was conducted using two different samples within the Faculty of Architecture, Computing \& Humanities:

- 140 undergraduate Level 4 Law students on a Law of contract course

- 52 postgraduate Level 7 Computing students on Database Architectures and Administration course 
Problem-solving and analytical skills are essential for both law practitioners and IT specialists (Database Administrators).

The University of Greenwich uses Panopto as a video-based software. Panopto allows lecturers to produce recordings with embedded power points/screen capture/ external sources/etc. The recordings are accessible via Panopto App or embedded into the University Virtual Learning Environment - Moodle. Both lecturers used Panopto to pre-record relevant content that was made available to students before face-to-face contact time.

\subsection{Law cohort - teaching and learning strategy}

The cohort chosen for this case study comprised first-year law students on the undergraduate LL.B law programme. These students were studying a compulsory law of contract course. Most of the 140-strong cohort were students entering Higher Education for the first time, following study in Further Education. The course attracts low numbers of mature students and only a small percentage of international students.

The law of contract is one of the seven foundations of legal knowledge, which all students must pass in order to progress. Students are required to develop a sound knowledge of the subject and a range of skills to support them in practically applying the law to factual scenarios incorporating problems to be addressed. These skills include research specific to law: legal research and referencing, strategies for analysing and evaluating the facts provided in a case study or scenario and then application of the appropriate legal principles to that context.

Students work with a range of research sources, including primary and secondary sources of law, which are in both electronic and paper form. Students must also develop the skills to solve problems within limited timescales and to work independently and as part of small groups.

Providing opportunities and time to support students in developing and scaffolding these skills is essential during Level 4.

The course was assessed by three written pieces of coursework, based on factual scenarios, and an exam, which also included similar scenarios with problems. The course's allocated weekly contact time consisted of a two-hour, large-group session and an hour's seminar session.

Materials for teaching and learning and assessment were constructively aligned, throughout the teaching, with all forms of summative assessment. An engaging, contextual scenario (based on a music festival held on campus) was used as the backdrop for all the derivative scenarios, both in the pre-released material and at every stage of teaching/learning, whose problems the students had to address.

Prior to attending the weekly large-group session, students listened to pre-recorded Panopto presentations. The recorded sessions provided an overview of the key legal principles and relevant legal cases for a topic. Students were provided with a course handbook containing notes and case law with blank spaces for recording information given via the Panopto. The flexibility of access to the advanced material helped to promote independent learning as students were able to choose when and how they engaged with the content. 
A different factual scenario was used at the start of each recording to set the context for the topic area. This supported students in developing an understanding of how the subject matter would be applied to the scenario. This scenario would then be re-visited in the large group.

The teaching material used in the two-hour lecture slot was designed to stimulate active engagement and to support development of a deeper knowledge of the pre-released topic areas.

Students attending large group sessions were asked to bring in some form of technology to create an interactive learning environment, as supported by SCALE-UP - the Student Centred Active Learning Upside-down Pedagogy (Beichner, 2006).

Students then worked on a range of activities, including multiple choice questions (Hot Potato activities), short-answer questions, problem-solving case scenarios, legal research activities, discussions, referencing activities and development of specific strategies to apply the law - all aimed at consolidating knowledge and developing problem-solving skills.

The one-hour seminar session allowed students to work in smaller groups on applying law to case scenarios, thus encouraging deeper learning and giving the opportunity to receive more personalised feedback.

\subsection{Computing cohort - teaching and learning strategy}

The cohort that was chosen for study in the department of Computing consisted of fifty-two Masters-level students, the majority of them international. These students were new to this country, to university-level education and to the flipped method of teaching and learning. The cohort traditionally presents a mixture of young students, mature students and part-time students with work experience.

The subject of the course is advanced database management and administration, technically complicated and challenging. The course requires students to acquire in a short period of time (twelve weeks) not only a comprehensive knowledge of the subject but also a considerable number of practical skills. Among these are, specifically, problem-solving skills, as any Database Administrator employer requires an investigative mind set and the ability to think fast and to solve complex problems in a time-pressured environment.

Prior to the in-class session, students were provided with a video lecture consisting of a narrated PowerPoint presentation as well as a live demonstration of the database system in action. The lecturer used Panopto to record the videos. The students also had access to the pdf version of the PowerPoint presentation used in the video. The students were encouraged to research other online material on the topic, including online DBA forums and various YouTube videos.

For the practical assignments, each student was given a Virtual Machine with all necessary software installed, supplying an individual environment where a student could practise without affecting other students' work. 
In-class time was divided between one hour of various interactive activities and two hours of supervised lab. The interactive activities were very important and aimed at verifying how well the students understood the material presented in the video lectures. They also helped the students to understand how to apply theoretical knowledge to real-life scenarios and revealed to what extent the students were able to compare and contrast different aspects of the topic.

Usually, the in-class session started with a quiz based on the video lecture: students first discussed the questions in pairs and then the pairs each presented their answers and arguments to the whole group. Thus, it was possible to check how well students had prepared, as well as to encourage them to watch videos regularly and engage with the content. The activity also provided the lecturer with a sense of the overall progress of the students and of which parts might need to be revisited if they still posed challenge.

After the quiz, the interactive activities varied from week to week, but they included: discussion about the results of the previous week's practical lab assignments; group discussions about common Database Administrator (DBA) problems and possible solutions; simulation of the reallife scenarios through a 'DBA vs. Users' interactive game. The supervised lab assignments required the students to complete various tasks in their Virtual Machines.

After the lab, the students were required to upload a short report, together with their answers to the reflective lab questions. The students' uploads were marked and individual feedback was provided weekly. Also, generic feedback was offered during the next interactive session, as a way of ensuring that the students had a sense of continuity from one week to the next and did not lose sight of the overall context behind each week's tasks.

\section{Research methods and findings}

For the purposes of this study, a set of two data sources were taken into consideration.

The first one was a standard course-evaluation survey, containing questions related to student satisfaction on the course. This survey provided an overall picture of students' experience of the new teaching method.

The summary of the data on both courses was positive. The students on both courses enjoyed the flipped learning approach and provided a very positive generic feedback:

> "Interesting teaching format. Great class discussion and the Quiz Time is highly helpful." (Student A)

$>$ "The way this course was taught is very interactive and helped me to learn new things." (Student B)

> "Flipped classroom' is really beneficial for student whose first language is not English and it gives student a very flexible approach to prepare for classes and discussion topics." (Student C) 
> "Very good teaching format. Videos and labs were very useful in completion of coursework." (Student D)

> "Probably the most useful database course which I had and a solid wrap up of the courses which I have taken since first year. New teaching method introduced 'Reverse classroom' which challenges your knowledge and helps to remember and pick the most useful content from the course." (Student E)

> "Challenging but also enjoyable it made my understanding easier and developed my skills of independent work further."

> "Pre-recorded sessions helped develop my understanding and made me more confident."

> "I found it engaging and student friendly (keeping concentration)."

> "The combination was very helpful however in the beginning it was challenging to keep up with everything."

However, as the purpose of this case study was to find out the impact the flipped classroom approach had on students' developing problem-solving skills, a more focused survey was designed and distributed to students via Survey Monkey. Both cohorts were asked mainly the same questions, with a few additional examples added within some questions - e.g. questions 1 and 18 were subject-specific.

[In the attachment, you will find a list of all questions. However, owing to limitations in the scope of this paper, some questions are omitted from the summary.]

The sample of the voluntary survey was relatively large, as, out of 140 Law students, fifty-nine took part in the survey and, out of fifty-two Computing students, twenty-four took part in the survey. The survey was conducted at the end of semester 1 .

\section{Putting flipped into practice}

This research identified a few areas that influenced the students in developing their problemsolving skills: what preparation was done prior to the in-class sessions, what activities were helpful during the in-class interactive sessions and whether the students were engaged with the course after in-class time.

In the first instance, students were asked about their pre-class engagement with various content. The questions differed slightly, as law students were asked about specific documents, whereas computing students were asked about relevant pdf.s in general. Figure 1 indicates that an overwhelming majority in both cohorts engaged with the videos and/or written documents (pdf.s, case studies and statutes). 
Case Studies

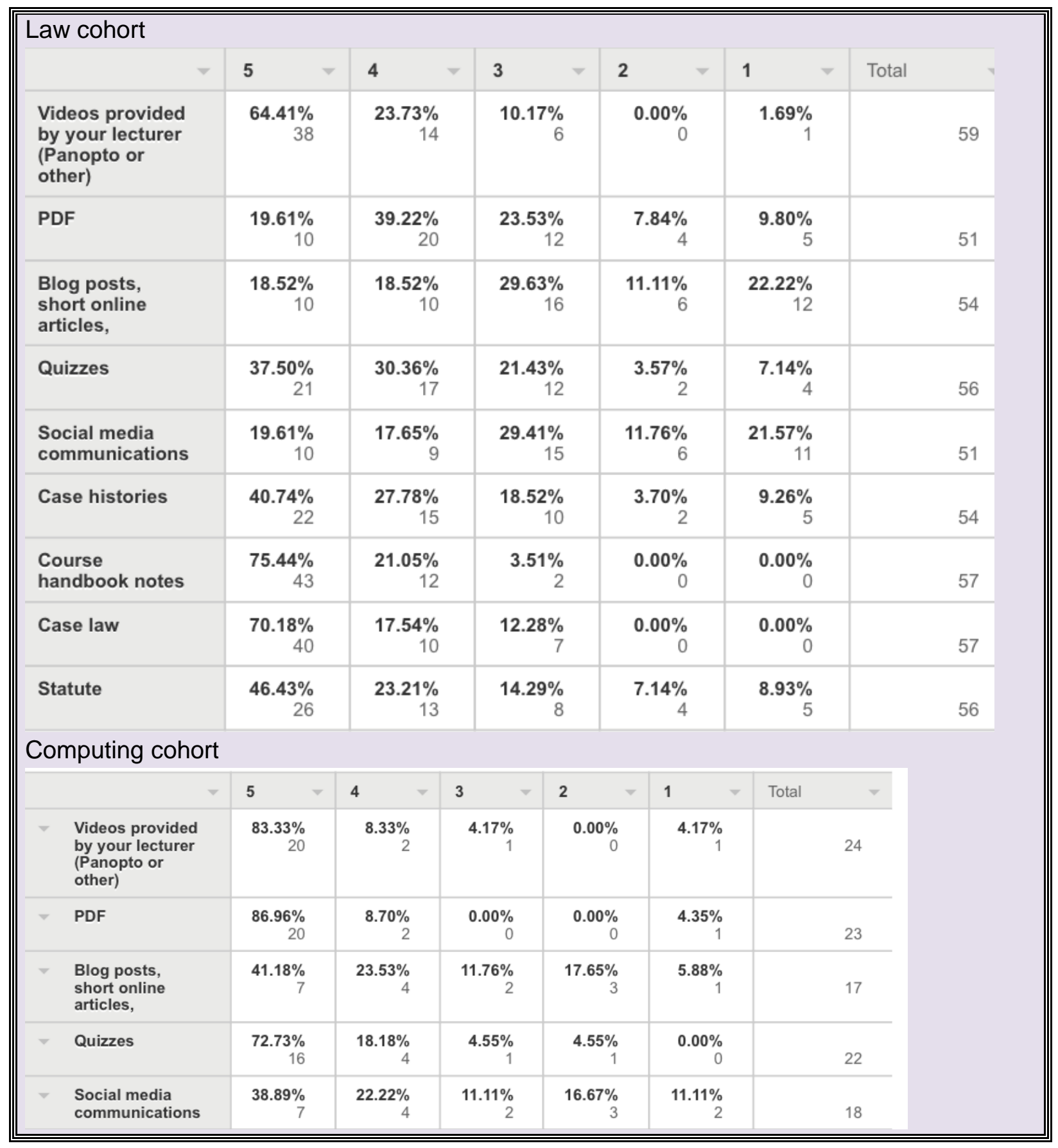

Figure 1: Results from question 1. What type of content did you engage with prior to the lecture/large group sessions and was it useful? Please rate on a scale of $1=$ least useful to $5=$ very useful.

As one of the crucial parts of the flipped classroom approach is engagement with the advanced content, and as the most content was given in the form of videos, the students were asked about the regularity of their watching of these. As is evidenced, only a small percentage of students rarely or never engaged with the videos. 


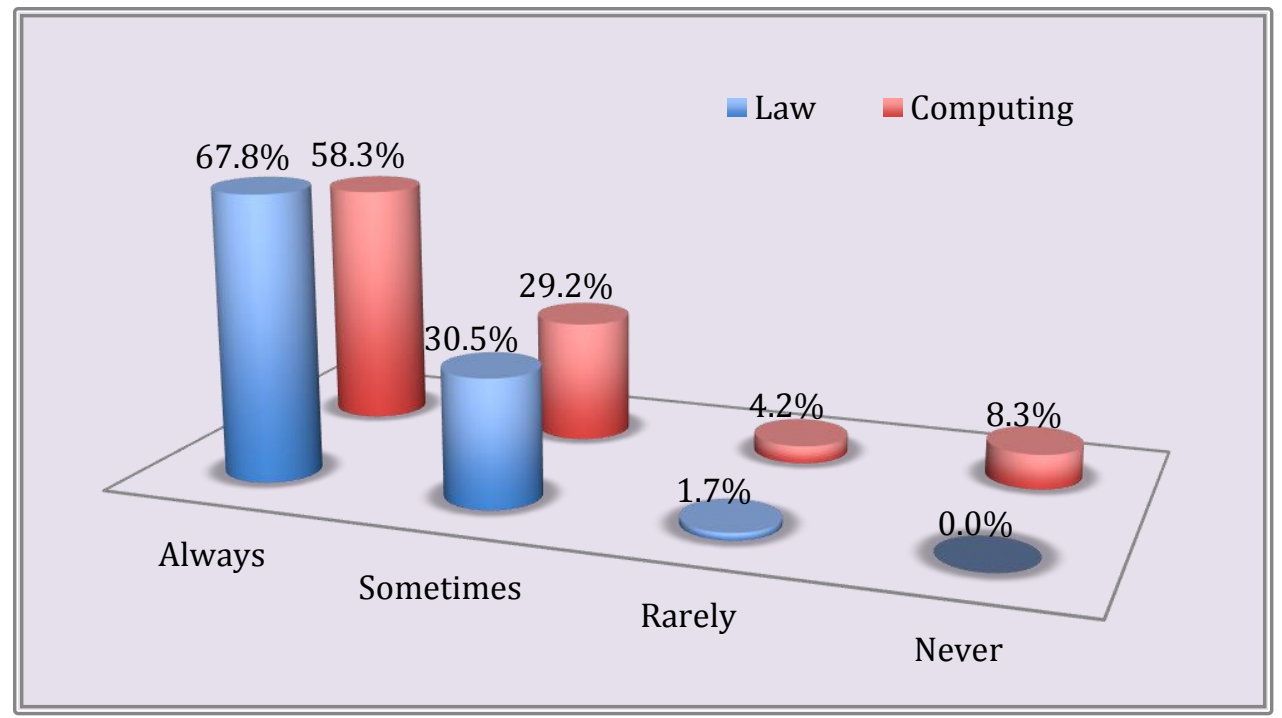

Figure 2: Results from the question 4. Do you watch the videos before the lecture session?

Advocates of the flipped classroom suggest that students have the opportunity to watch the recordings on multiple occasions. This was therefore the next question that both student cohorts responded to (Figure 3). Here the answers varied.

As the majority of the MSc computing cohort consists of international students, it was identified that more than one third of the cohort (37.5\%) did watch the videos twice or more before coming to the class. This result indicated that pre-recorded videos are a valuable resource for international students (English being their second language), if they are to engage with the course without being embarrassed in front of their peers by not having understood the material from one viewing.

The law results demonstrated that a significant number of law students watched the material before the lecture: $86.4 \%$, with only $13.6 \%$ watching the material twice in advance of the class.

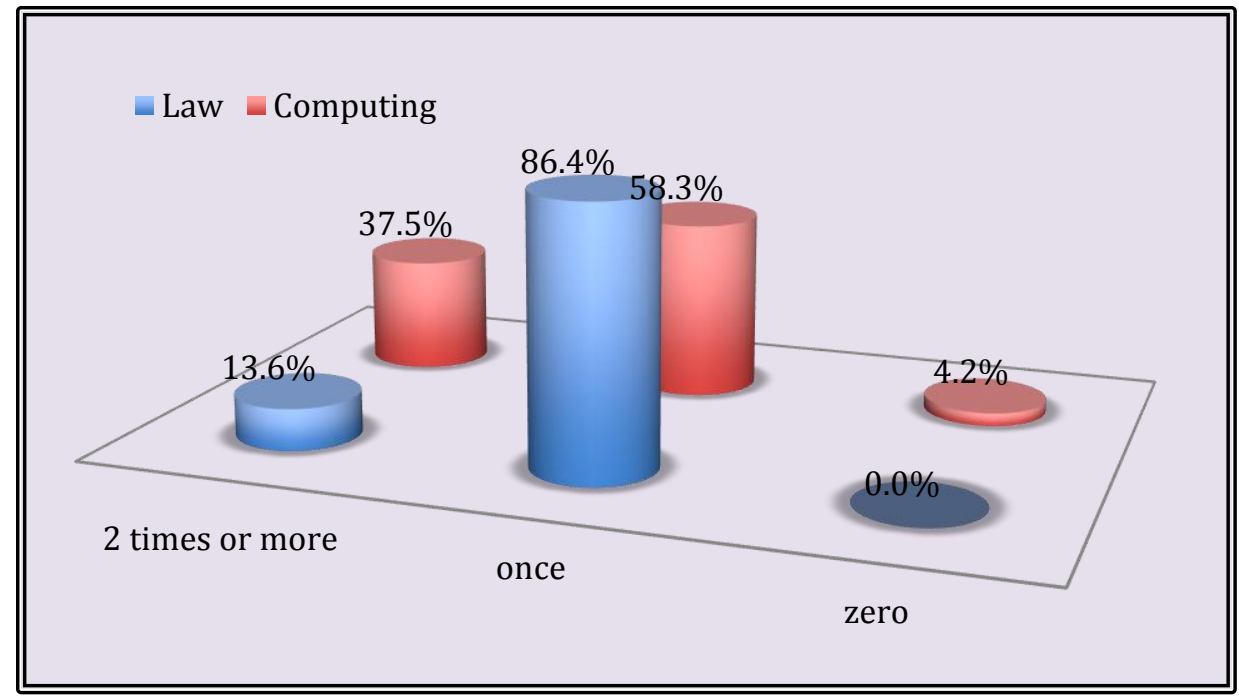

Figure 3: Results from the question 5. How many times on average do you watch the material before coming to the class? 
The results of the survey also showed that the majority of students from both cohorts did revisit course videos after the in-class group sessions to support and/or to clarify their learning (see Figure 4). This was a particularly useful insight, as it evidences the willingness of students to take responsibility for their own learning and confirms the validity and usefulness of providing students with pre-recorded materials.

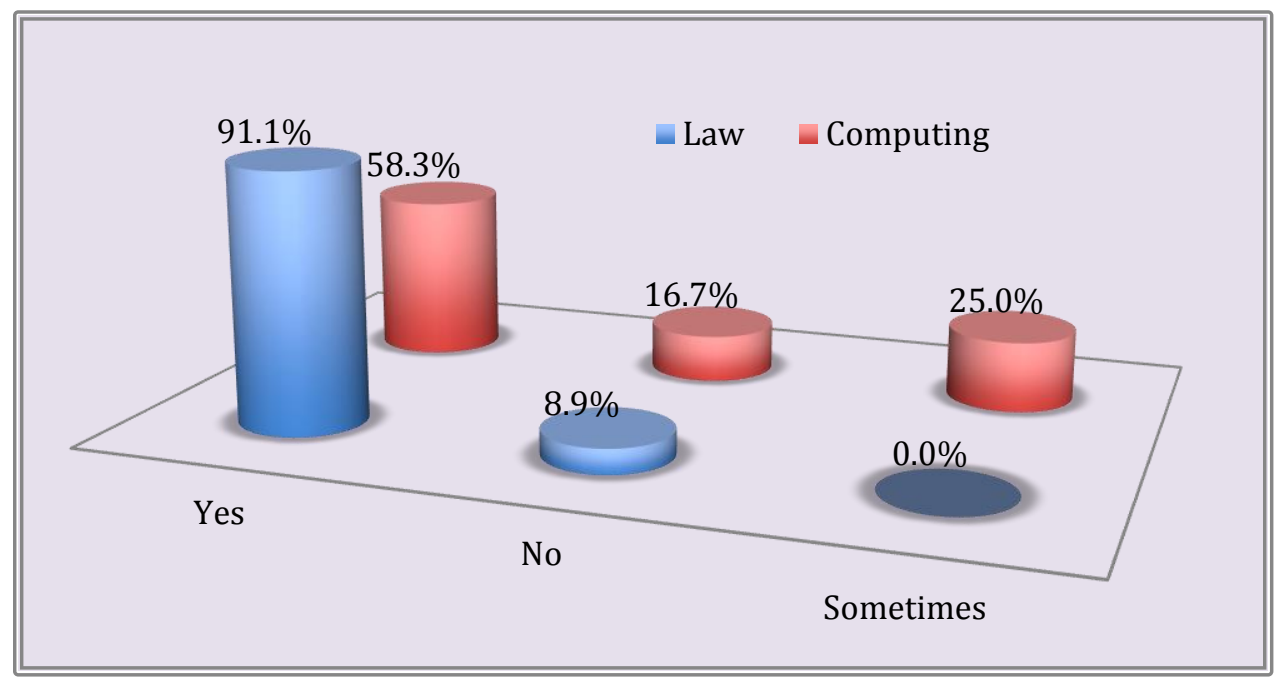

Figure 4: Results from the question 12. After the large group session/lecture do you revisit videos to support/clarify your learning?

During in-class time, large group sessions were the main vehicle for putting the learnt material into practice and applying it to real-life scenarios and problems. The students had a chance to discuss and debate their possible solutions. So, it was not a surprise to discover that the majority of the cohort felt that the in-class group sessions helped them to develop problemsolving skills (see Figure 5).

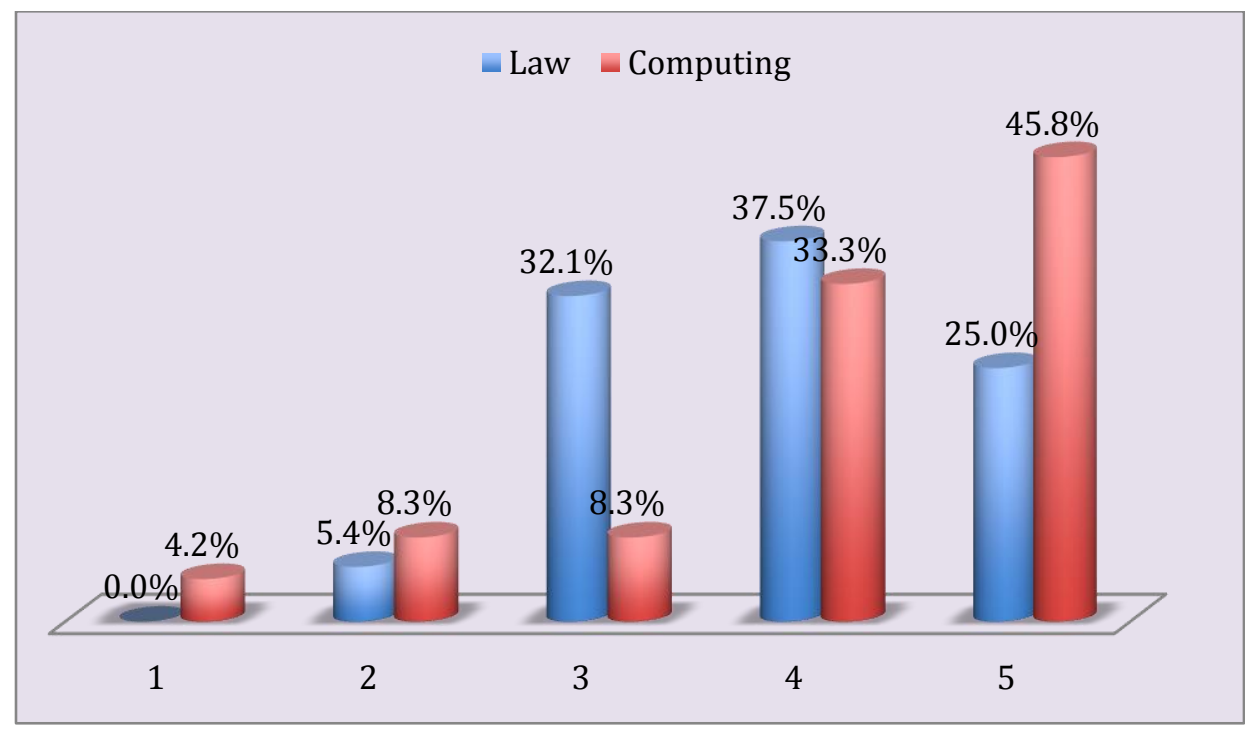

Figure 5: Survey results from question 10. The large group session has helped me to develop problem-solving skills. Please rate on a scale of $1=$ strongly disagree to $5=$ strongly agree. 
Students were also asked about whether the flipped classroom method inspired them to carry out further research in their course (Figure 6). The results indicated that the overwhelming majority had chosen either 'yes' or 'sometimes' in their answers.

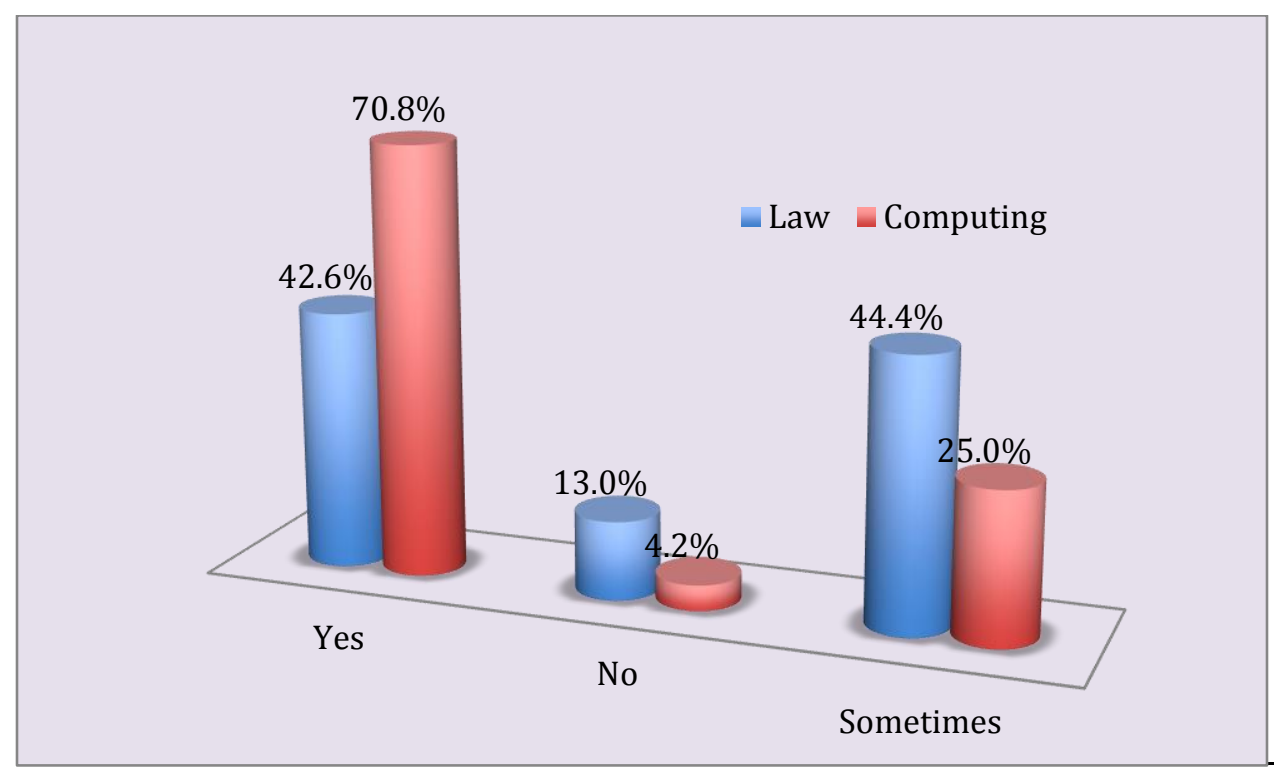

Figure 6: Survey results from question 11. Has the large group session inspired you to carry out further research in your course?

An overwhelming majority of students in both cohorts participating in the survey felt that the flipped classroom enhanced their skills in general (see Figure 7) and, particularly, independent study skills, problem-solving techniques, research skills, working in groups, etc. (see Figure 8).

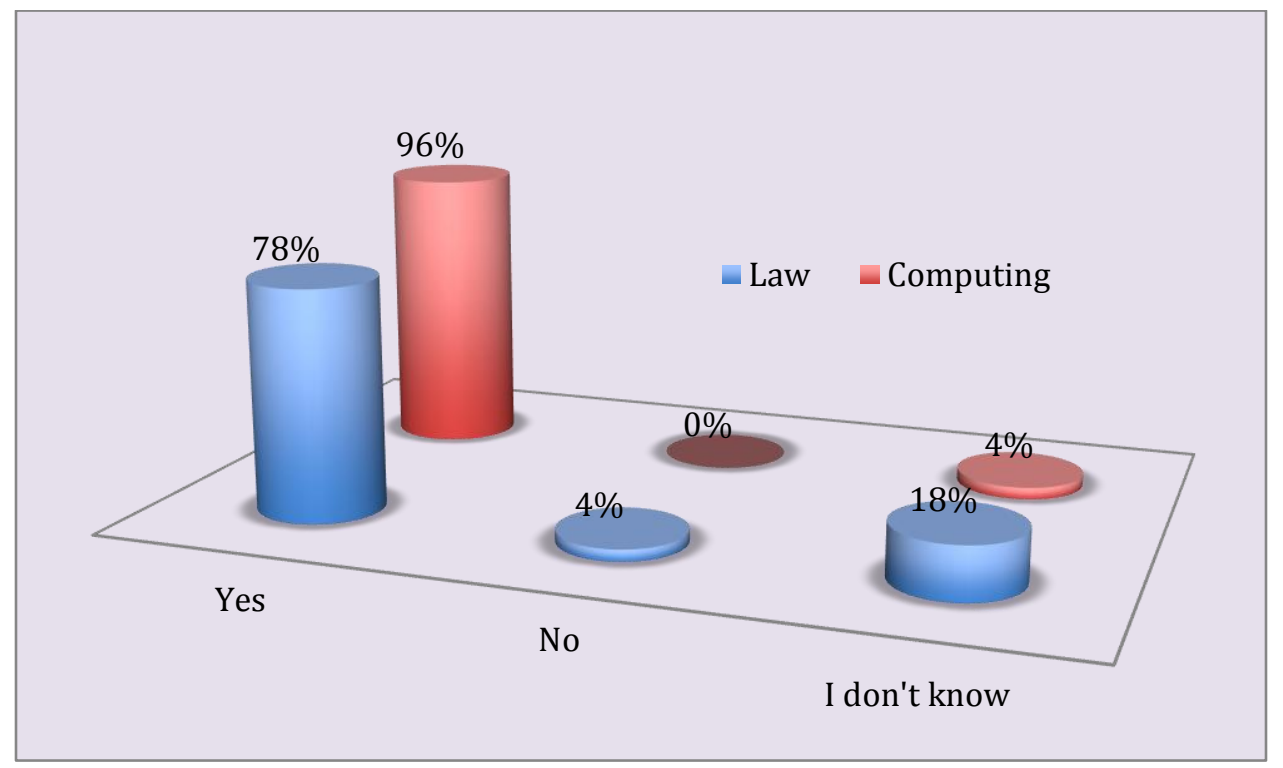

Figure 7: Survey results from Q17. Using flipped learning as a basis for learning has enhanced my skills. 


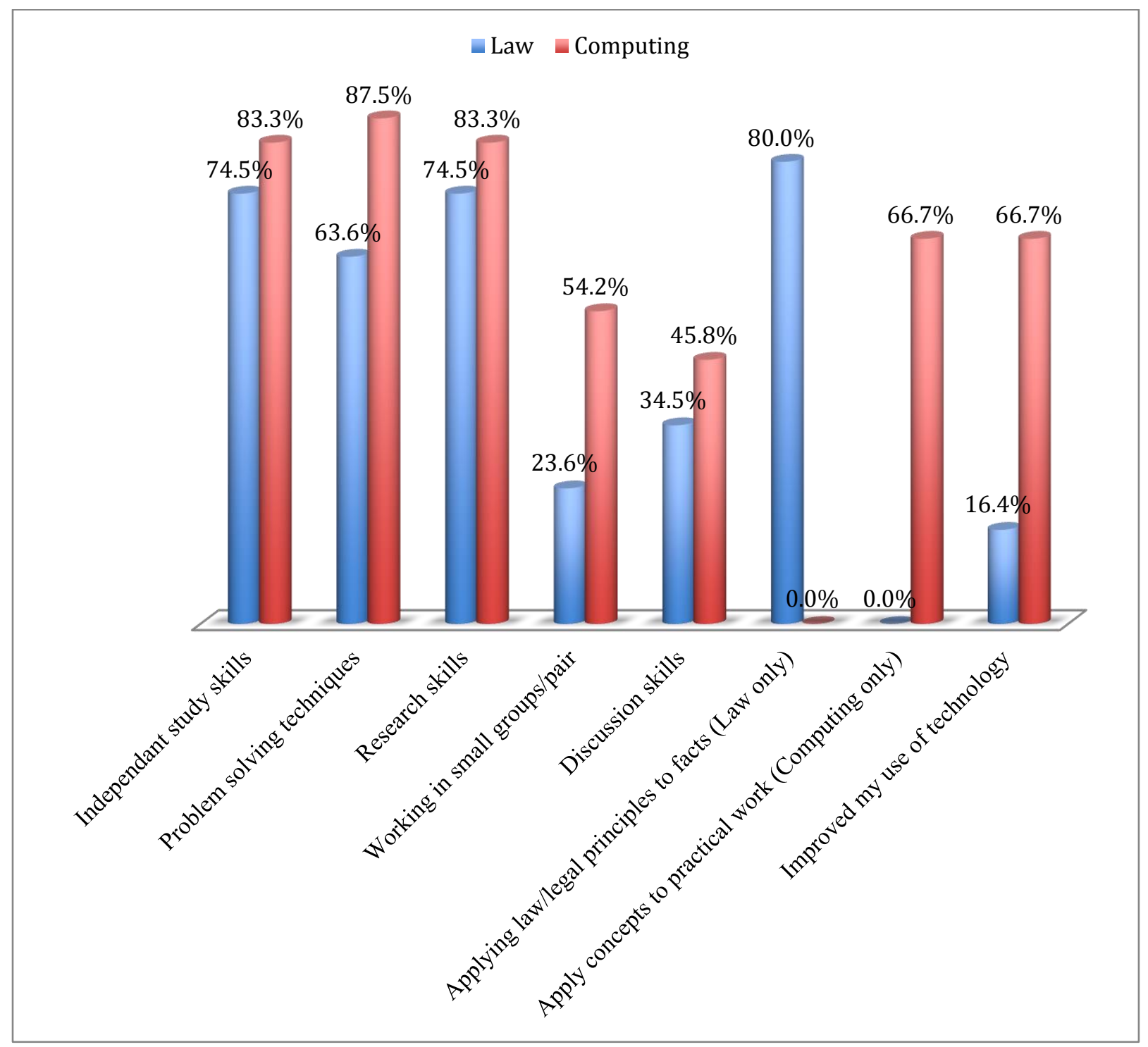

Figure 8: Survey results from Q18. Using the flipped classroom approach has developed my problem skills.

When the students were asked to explain why they found the flipped classroom activities useful, they mentioned various aspects and highlighted some useful perspectives.

For example:

- the flipped classroom activities encouraged their learning and understanding of the course material;

- it helped them to have a clearer understanding of the subject topic;

- it helped them to find the right approach to the problem that they were facing;

- it helped to learn from peers during the interactive session;

- the debates during the large group sessions helped to correct their misunderstandings and errors; 
- it provided a practical approach to real-world problems and it also made the learning experience interesting and enjoyable;

- it gave law students the opportunity to practice specific strategies for solving problemstyle questions and for giving advice to potential clients.

Those findings are consistent with the results reported in Krathwohl (2002), Kim et al (2014) and Davis et al (2013) on the higher-order thinking skills, as well as in studies by Asef-Vaziri (2015:

72) and Mayer (2002). They are also consistent with advocates of the flipped classroom and the development of problem-solving skills explored by Asef-Vaziri (2015) and Mayer (2002). Additionally, these findings back up the notion of the enhancing of students' collaboration in flipped classroom learning (Halili et al, 2014).

This approach created an active learning setting where students engaged with real-world problems; it enabled their application of basic knowledge acquired from engaging with the videos and, in a 'safe' environment, stimulated discussion/debate of various possible solutions to a question or to the problems of a scenario. That gave students confidence in their ability to transform things they knew into things they could do.

It also showed them that they could be in control of their understanding and memory of the content (the Bloom's Taxonomy lower-level thinking skills) and did not need to be afraid (or embarrassed) to re-visit the fundamentals if necessary.

Conversely, when asked about why, in their opinion, the flipped classroom activities were not useful, the criticisms mentioned by students were as follows:

- some activities were too long;

- some students prefer working alone rather than in groups;

- group presentations did not work as some students did not participate in the group work;

- some videos were too long;

- students were less keen on the flipped classroom activities;

- some students felt they missed out on lectures;

- some students found it challenging to understand the concept of flipped learning.

Considering these criticisms, it would be relatively simple for the lecturers to revisit and review their flipped classroom content to make appropriate changes. Teaching first-year students highlighted that it was vital to revisit, sometimes more than once, the concept of the flipped classroom to explain its rationale and intention again; by supporting students' understanding, lecturers might thus secure their commitment to this chosen pedagogy.

The background research review highlights the importance of varying both the activities (to address different learning styles) and their pace. On this basis, it is clear that further experimentation and practice is required to achieve a workable contact-time balance in terms of the amount and type of flipped classroom activities. 


\section{Conclusions and looking ahead}

This research has highlighted that, although two different cohorts engaged in this study (different in size, cultural backgrounds, age groups, subject and level of study), the flipped classroom approach did enhance students' learning experience and enabled them to develop problem-solving skills (crucial for both law and computing students and practitioners), in addition to a range of other graduate skills.

The findings offer clear evidence that the experience of both cohorts was similar in terms of benefits gained and consistently-positive student feedback. The structure of the flipped classroom sessions and the clearly-thought-through and constructively-aligned teaching activities enabled students to acquire a range of different skills and become both confident and competent in their use.

Overall, the results support this paper's claim that the flipped classroom can be used to enhance the student experience and that it provides the scope to support students in developing problem-solving skills.

Adopting this approach might present challenges for the lecturer. These are highlighted below:

- The challenges of becoming a flipped academic:

- supporting students to adapt to student-centred teaching style;

- the time involved in providing continuous feedback to students and adjusting to being a 'guide on a side' rather than a 'sage on the stage'.

- Time involved in both planning and redesigning teaching materials:

- recording videos;

- creating material for interactive sessions;

- creating appropriate assessment to reflect the method of teaching.

- Managing the large group:

- finding suitable teaching space;

- flexibility (a must) in personal teaching techniques;

- being comfortable in engaging with any questions that may be offered by the students;

- ensuring maintenance of the focus of each session and taking students with you in terms of their understanding and consolidation of learning.

- Level 4 students new to HE may find it initially challenging to get used to the method.

However, owing to the limited scope of this study, these issues were not explored; a further study to examine the above would be beneficial.

Also, future study would benefit from exploring the benefits of the flipped classroom for the development of other skills, including reflection, deeper comprehension and so on; such an investigation would require the researchers to study participants for an extended period of time and under a different research lens. Since the flipped classroom literature rarely adopts longitudinal studies, such an approach is recommended for further exploration. 
Finally, as some recent studies have looked at how student-centred learning and the individualised learning opportunities offered by the support of the flipped classroom can have an impact on the efficacy of the flipped-learning design in raising students' attainment and increasing their engagement, an empirical and longitudinal study to explore this notion would be beneficial (e.g. Hibbard et al, 2016; O'Flaherty and Phillips, 2015; Little, 2015).

Moreover, based on the results of this research and our classroom observations, we can conclude that the flipped learning approach does present numerous benefits in addition to those mentioned already. The attendance at in-class sessions was excellent and did not confirm the common anecdotal and sceptical opinion that if students watch the provided videos they will not come to the class. Making group sessions interactive, practical and interesting attracted students even more than the traditional lectures. Finally, though we have noted from the results the need for some adjustments to assessments, types of flipped classroom activities and the content and length of videos, further research would be needed to provide empirical data.

\section{Reference list}

Asef-Vaziri, A. (2015) 'The Flipped Classroom of Operations: A Not-For-Cost-Reduction Platform.' Decision Sciences Journal of Innovative Education, 13(1), 71-89.

Beichner, R (2006) 'North Carolina State University: SCALE-UP.' In: Oblinger, D. (ed.), Learning Spaces. Boulder, CO: Educause.

Bergmann, J. and Sams, A. (2012) 'How the Flipped Classroom is Radically Transforming Learning.' The Daily Riff. Available at: http://www.thedailyriff.com/articles/how-the-flippedclassroom-is-radically-transforming-learning-536.php (Accessed: 04 April 2017).

Bernett, R., Parry, G and Coate, K. (2001) 'Conceptualising Curriculum Change.' Teaching in Higher Education, 6, 435-449.

Davies, R. S., Dean, D. L. and Ball, N. (2013) 'Flipping the classroom and instructional technology integration in a college-level information systems spreadsheet course.' Educational Technology Research and Development, 61(4), 563-580.

Flipped Learning Network (FLN). (2014) The four pillars of F-L-I-P. Available at: http://flippedlearning.org/wp-content/uploads/2016/07/FLIP handout FNL Web.pdf (Accessed: 12 March 2016).

Fulton, K. (2012) 'Upside down and inside out: Flip Your Classroom to Improve Student Learning.' Learning \& Leading with Technology, 39(8), 12-17.

Halili, S. H. and Zainuddin, Z. (2015) 'Flipping the classroom: What we know and what we don't.' The Online Journal of Distance Education and e-Learning, 3(1), 28-35. 
Halili, S. H., Abdul Razak, R. and Zainuddin, Z. (2014) 'Enhancing collaborative learning in flipped classroom.' Australian Journal of Basic and Applied Sciences, 9(7), 147-149.

Hamdam, N., McKnight, P., McKnight K. and Arfstrom K.M. (2013) The flipped learning model: $A$ white paper based on the literature review titled - A Review of Flipped Learning. Available at http://flippedlearning.org/wp-content/uploads/2016/07/WhitePaper_FlippedLearning.pdf (Accessed: 12 September 2015).

Hannafin, M., Hill, J. and Land, S. (1997) 'Student-centred learning and interactive multimedia: status, issues and implication.' Contemp Educ, 68(2), 94-99.

Hibbard, L., Sung, S. and Wells, B. (2016) 'Examining the Effectiveness of a Semi-Self-Paced Flipped Learning Format in a College General Chemistry Sequence.' Journal of Chemistry Education, 93, 24-30.

James, A. J., Chin, C. K. H. and Williams, B. R. (2014) 'Using the flipped classroom to improve student engagement and to prepare graduates to meet maritime industry requirements: a focus on maritime education.' WMU Journal of Maritime Affairs, 13(2), 331-343.

Kim, M. K., Kim, S. M., Khera, O. and Getman, J. (2014) 'The experience of three flipped classrooms in an urban university: An exploration of design principles.' The Internet and Higher Education, 22, 37-50.

King, A. (1993) 'From sage on the stage to guide on the side.' Coll Teach, 41(1), 30-35.

Krathwohl, D.R. (2002) 'Revision of Bloom's taxonomy: an overview.' Theory Pract, 41(4), 212218.

Kong, S. C. (2014) 'Developing information literacy and critical thinking skills through domain knowledge learning in digital classrooms: An experience of practicing flipped classroom strategy.' Computers \& Education, 78, 160-173.

Little, C. (2015) 'The flipped classroom in further education: literature review and case study.' Research in Post-Compulsory Education, 20(3).

Mayer, R. (2002) The promise of educational psychology: Learning in the content areas. Upper Saddle River: Merrill.

Mazur, E. (1991) 'Can We Teach Computers to Teach?’ Computers in Physics, 5 (1), 31-38.

Mazur, E. (2009) 'Farewell, Lecture?' Science, 323, 50-51.

NMC (2014) Horizon Report 2014: Higher Education Edition. Austin, TX: The New Media Consortium.

Nederveld, A. and Berge, Z. L. (2015) 'Flipped learning in the workplace.' Journal of Workplace Learning, 27(2), 162-172. 
O'Flaherty, J. and Phillips, G. (2015) 'The use of flipped classrooms in higher education: A scoping review.' Internet and Higher Education, 25, 85-95.

Pallis A.A. and Ng, A. (2011) 'Pursuing maritime education: an empirical study of students' profiles, motivations and expectations.' Maritime Policy \& Management: The flagship journal of international shipping and port research, 38(4), 369-393.

Pogrow, S. (1990) The HOTS approach to using computers with at-risk students. Tucson, AZ: Thinking with computers.

Sharples, M., Adams, A., Ferguson, R., Gaved, M., McAndrew, P., Rienties, B., Weller, M. and Whitelock, D. (2014) Innovating Pedagogy 2014: Open University Innovation Report 3. Milton Keynes, UK: The Open University.

Strayer, J. (2012) 'How learning in an inverted classroom influences cooperation, innovation and task orientation.' Learning Environments Research, 15(2), 171-193. 